\title{
EFFECTS OF THE DURATION OF INTERVAL TRAINING REST PERIODS ON SELECTED HEART RATES
}

\author{
AREND BONEN, B.A., M.S., Ph.D.* \\ Physical Fitness Research Laboratory, Department of Physical Education \\ University of Illinois at Urbana-Champaign, Champaign, Illinois 61820, USA \\ *Current Address: Human Performance Laboratory, Sir Charles Tupper Medical Building, \\ School of Physical Education, Dalhousie University, Halifax, Nova Scotia, Canada
}

\section{Introduction}

Interval training has been widely advocated as an effective training stimulus (Counsilman, 1968). Interspersing the exercise bouts with rest periods can increase the quantity and intensity of exercise than can be sustained within a given time period (Åstrand et al., 1960; Christensen et al., 1960), presumably since the rest periods prevent an excess accumulation of lactic acid (Christensen et al., 1960). In this regard, frequent short rest periods are more effective than infrequent but longer rest periods (Müller, 1953).

The duration of the rest intervals, in relation to the duration and intensity of the exercise bouts, constitutes an important training variable (Counsilman, 1968). The principal stimulus for the physiological adaptation to exercise, however, is the duration of exercise rather than the duration of the rest periods (Åstrand et al., 1960; Christensen, 1960; Landry, 1967). Yet, the duration of the rest period can modify, quite dramatically, the intensity of exercise (Christensen et al., 1960; Karlsson et al., 1967). It may then be hypothesized that an interval training programme with long rest periods is less effective than a similar programme with short rest periods. The purpose of the present investigation therefore was to assess the relative effectiveness of two interval training programmes which consisted of repeated three minute exercise bouts interspersed with one or three minute rest periods.

\section{Methodology}

Fifteen untrained male volunteers participated in the investigation (Table 1). The control group consisted of five subjects and the remaining ten subjects were divided into two groups which were matched on the basis of their maximal aerobic capacity. These two groups trained three times per week for eleven weeks by stepping on an 18 inch bench. For both groups each exercise session was composed of ten, three-minute work bouts. One group rested one minute and the other group rested three minutes between exercise bouts. The initial stepping rate was 28 steps per minute and was increased one step per minute per week. The stepping rate during the last week of training was 38 steps per minute, stepping cadence maintained with a metronome. Criterion measurements were obtained from two standardized tests. Upon arrival at the laboratory, the subjects voided urine and were weighed. ECG electrodes? were attached and the subjects rested in a supine position for thirty minutes. The resting heart rate was defined as the mean heart rate of the last ten minutes of rest.

A progressive 'all-out' treadmill run followed the rest period. This test consisted of repeated five minute runs at $7 \mathrm{mph}$, at progressively increased grades, with a ten minute rest period between runs, until the subject was unable to complete a run. The treadmill grade was raised $2.5 \%$ between runs. From the first five minute run

TABLE 1

CHARACTERISTICS OF THE SUBJECTS

\begin{tabular}{|c|c|c|c|c|c|}
\hline Group & $N$ & & $\begin{array}{l}\text { Age } \\
\text { (Years) }\end{array}$ & $\begin{array}{l}\text { Height } \\
\text { (cm) }\end{array}$ & $\begin{array}{l}\text { Weight } \\
(\mathrm{kg})\end{array}$ \\
\hline Control & 5 & $\begin{array}{l}\mathrm{X} \\
\text { range }\end{array}$ & $\begin{array}{l}19.4 \\
(18-24)\end{array}$ & $\begin{array}{l}177.6 \\
(167.6-185.4)\end{array}$ & $\begin{array}{l}71.3 \\
(63.6-76.1)\end{array}$ \\
\hline $\begin{array}{l}3 \mathrm{~min} . \\
\text { rest }\end{array}$ & 5 & $\begin{array}{l}\bar{X} \\
\text { range }\end{array}$ & $\begin{array}{l}18.4 \\
(18-19)\end{array}$ & $\begin{array}{l}182.0 \\
(170.2-195.6)\end{array}$ & $\begin{array}{l}74.3 \\
(70.5-80.4)\end{array}$ \\
\hline $\begin{array}{l}1 \text { min } \\
\text { rest }\end{array}$ & 5 & $\begin{array}{l}\bar{X} \\
\text { range }\end{array}$ & $\begin{array}{l}19.6 \\
(19-23)\end{array}$ & $\begin{array}{l}170.5 \\
(165.2-177.8)\end{array}$ & $\begin{array}{l}69.7 \\
(61.6-87.6)\end{array}$ \\
\hline
\end{tabular}


of this test ( $7 \mathrm{mph}, 5 \%$ grade), the heart rate recorded between 4:45-5:00, and the heart rate obtained during the last 15 seconds of the last full minute of the 'all-out' run, were designated as the submaximal and maximal heart rates, respectively. The stability of the standardized tests was evaluated by retesting one control and nine experimental subjects prior to training. From these individuals the lowest heart rates obtained on one of the two tests were designated as the pre-training data.

Statistical analyses of the data, except for the test-retest reliability coefficients, were performed with non-parametric statistics since the groups were small and heterogeneous. Within-group and between-group analyses, based on difference scores (i.e., pre-training minus the post-training results) were performed with the Walsh test and the Mann-Whitney $U$ test, respectively (Siegel, 1956).

\section{Results}

High test-retest reliability coefficients were obtained for the submaximal $(r=0.88)$ and maximal exercise heart rates $(r=0.78)$. A moderate test-retest correlation was found for the resting heart rates $(r=0.58)$.

\section{TABLE 2}

\section{HEART RATES BEFORE AND AFTER AN 11 WEEK REST-VARIED INTERVAL TRAINING PROGRAMME}

\begin{tabular}{|c|c|c|c|c|c|c|c|c|c|c|c|}
\hline \multirow[t]{2}{*}{ Group } & \multirow[t]{2}{*}{$\mathbf{N}$} & & \multicolumn{2}{|c|}{$\begin{array}{l}\text { Resting Heart } \\
\text { Rate (b/min) }\end{array}$} & \multirow[b]{2}{*}{ Diff. } & \multicolumn{3}{|c|}{$\begin{array}{l}\text { Submaximal Heart } \\
\text { Rate (b/min) }\end{array}$} & \multicolumn{2}{|c|}{$\begin{array}{l}\text { Maximal Heart } \\
\text { Rate (b/min) }\end{array}$} & \multirow[b]{2}{*}{ Diff. } \\
\hline & & & Pre & Post & & Pre & Post & Diff. & Pre & Post & \\
\hline \multirow[t]{2}{*}{ Control } & 5 & $\bar{x}$ & 63.6 & 64.4 & -0.8 & 184.3 & 184.3 & 0.0 & 191.8 & 193.6 & -1.8 \\
\hline & & SD & \pm 12.1 & \pm 15.1 & \pm 7.1 & \pm 13.7 & \pm 17.5 & \pm 5.4 & \pm 7.8 & \pm 6.8 & \pm 4.9 \\
\hline $3 \mathrm{~min}$. & 5 & $\bar{x}$ & 64.2 & 61.4 & 2.8 & 187.6 & 185.8 & 1.8 & 192.8 & 193.4 & -.06 \\
\hline rest & & SD & \pm 13.3 & \pm 12.5 & \pm 10.1 & \pm 4.4 & \pm 9.1 & \pm 5.0 & \pm 9.0 & \pm 8.5 & \pm 8.3 \\
\hline $\mathrm{Imin}$ & 5 & $\bar{x}$ & 62.6 & 52.6 & $10.0 \mathrm{ab}$ & 184.4 & 173.0 & 11.4abc & 199.6 & 193.4 & $6.2^{a b}$ \\
\hline rest & & SD & \pm 5.9 & \pm 3.9 & \pm 6.8 & \pm 8.6 & \pm 11.4 & \pm 4.5 & \pm 5.6 & \pm 3.4 & \pm 3.4 \\
\hline
\end{tabular}

a Significant difference within groups $(p<0.06)$.

b Significant difference between training groups and the control group $(p<0.05)$.

cSignificant difference between training groups $(p<0.05)$.

Analyses of the results within each group were based on difference scores (Table 2). In the control group, none of the parameters under investigation were altered significantly ( $p>0.06$ ). Significant reductions of the resting, submaximal and maximal heart rates were observed in the one minute rest group $(p<0.06)$. These parameters were not altered significantly in the three minute rest group $(p>0.06)$.

Comparisons among the three groups were also based on difference scores (Table 2). The changes in the heart rates of the three minute rest group were not significantly different from the changes observed in the control group $(p>0.05)$. In contrast, the changes in the resting, submaximal and maximal heart rates of the one minute rest group were all significantly greater than the changes in the heart rates of the control group ( $p<$ 0.05 ). Comparisons of the two training groups indicated that the reduction of the submaximal heart rates was significantly greater in the one minute rest group than in the three minute rest group ( $<<0.05$ ). Alterations of the other heart rates were not significantly different ( $p$ $>0.05)$.

\section{Discussion}

The relative effectiveness of two rest-varied interval training programmes was compared in the present study. Adaptive heart rate responses to training occurred more rapidly in the one minute rest group than in the three minute rest group.

Reductions of heart rates are commonly used to gauge the effectiveness of various training programmes (Saltin et al., 1968; Wilmore et al., 1970). The changes in the resting and exercise heart rates of the one and three minute rest groups, in comparison to the control group, were quite different. Significant decrements in the resting, submaximal and maximal heart rates in the one minute rest group are consistent with the data from 
other investigations (Ekblom et al., 1968; Saltin et al., 1969; Ekblom, 1970). Such reductions have been associated with concomitant increments in the arteriovenous oxygen difference (Ekblom et al., 1968), an increased cardiac stroke volume (Ekblom, 1970), or a combination of these effects (Saltin et al., 1968).

Assuming that the reduction of heart rates is indicative of adaptation to training or exercise, no demonstrable training effect occurred in the three minute rest group, since none of the criterion heart rates were altered significantly after an eleven week training programme. A very definite training effect did occur in the one minute rest group. However, since only the changes in the submaximal heart rates were significantly different in the two training groups, it cannot be stated conclusively that the exercise regimen with the one minute rest periods provided more effective training, yet the trend of the remaining data and the fact that the three minute rest group behaved like the control group do suggest that more definitive conclusions may result if training programmes are continued for longer periods of time. Pollock et at. (1969) have shown that meaningful evaluations of different training programmes require a considerable period of time. Short term training programmes may not differentiate fully the physiological alterations associated with training.

There is good reason to believe that training programmes with short rest periods are more effective than those with longer rest periods. It has been demonstrated that the demands on the oxygen transport system are significantly increased simply by reducing the duration of the rest interval without altering the exercise duration or intensity (Christensen et al., 1960; Karlsson et al., 1967). In addition, the intensity of exercise is the primary stimulus for the adaptive physiological responses observed during training (Shephard, 1968; Fox et al., 1973). Therefore, even though the work rate of the three minute exercise bouts was identical, it is not surprising that more pronounced training changes occurred in the one minute rest group than in the three minute rest group, since the intensity of training was more severe in the former group. Results of the present investigation are in good agreement with those of Yakovlev et al. (1961). They also found that during an anaerobic training programme the rate of adaptation of various physiological and performance variables occurred more rapidly in a one minute rest group than in a two or three minute rest group.

There seems to be little doubt that the duration of the rest period is a critical training variable. The intensity of training is not governed merely by the intensity of exercise but the duration of the rest period must also be considered. The practical significance of such considerations must not be forgotten. When limited training time is available, reducing the duration of the rest period shortens the total time required for training and at the same time this also provides a more effective training regimen. Alternatively, within a given time period more exercise can be performed when rest periods are shortened. In either instance the rest period may be used to suit the needs of the coach or the athlete to achieve an effective training programme.

\section{Acknowledgement}

The author wishes to thank Dr. B. D. Franks for his guidance and suggestions during the course of the investigation.

\section{REFERENCES}

1. ÅSTRAND, I., et al. Intermittent muscular work. Acta Physiol.Scand. 48: 448-453, 1960.

2. CHRISTENSEN, E. H. Intervallarbeit und intervalltraining. Int.Z.angew.Physiol. 18: 345-356, 1960.

3. CHRISTENSEN, E. H., et al. Intermittent and continuousrunning. Acta Physiol.Scand. 50: 269-286, 1960.

4. COUNSILMAN, J. E. The Science of Swimming. Toronto, Canada. Prentice-Hall, p. 199 ff., 1968.

5. EKBLOM, B., et al. Effect of training on circulatory response to exercise. J.Appl.Physiol. 24: 518-528, 1968.

6. EKBLOM, B. Effect of physical training on circulation during prolonged severe exercise. Acta Physiol.Scand. 78: 145-158, 1970.

7. FOX, E. L. et al. Intensity and distance of interval training programs and changes in aerobic power. Med.Sci.Sports. 5: 18-22, 1973.

8. KARLSSON, J., et al. Energikraven vid Löpning. Idrottsfysiologi, report 4, Framtiden, Stockholm, 1967. 
9. LANDRY, J. F. Adaptations of organic functions to continuous and intermittent exercise patterns in four male subjects. Doctoral dissertation, University of Illinois, Urbana, 1967.

10. MÜLLER, E. A. The physiological basis of rest pauses in heavy work. Qt.J.Exp.Cogn.Med.Sci. 38: 205-215, 1953.

11. POLLOCK, M. L., et al. Effects of frequency of training on working capacity, cardiovascular function, and body composition of adult men. Med.Sci. Sports. 1: 70-74, 1969.

12. SALTIN, B., et al. Response to exercise after bed rest and after training. Circulation. Suppl. 7, 1968.

13. SALTIN, B., et al. Physical training in sedentary middle-aged men. II. Oxygen uptake, heart rate, and blood lactate concentration at submaximal and maximal exercise. Scand.J. Clin. Lab.Invest. 24: 323-334, 1969.

14. SHEPHARD, R. J. Intensity, duration and frequency of exercise as determinants of the response to a training regime. Int.Z.angew. Physiol. 26: 272-278, 1968.

15. SIEGEL, S. Nonparametric Statistics for the Behavioural Sciences. Toronto, Canada. McGraw-Hill. pp. 83-87 and pp. 116-127, 1956.

16. WILMORE, J. H., et al. Physiological alterations resulting from a 10-week programme of jogging. Med.Sci.Sports. 2: $7-14,1970$.

17. YAKOVLEV, N. N., et al. Physiological and chemical adaptation to muscular activity in relation to length of rest periods between exertions during training. Sechenov.Physiol.J.USSR. 47: 56-59, 1961.

MEERINGS OF OTHER ORGANISATIONS.

III rd. EUROPEAN CONGRESS OF SPORTS MEDICINE. BUDAPEST, HUNGARY.

September 17th - 20th, 1974. (F.I.M.S. sponsored).

Registration commences Sept. 17th, followed by three whole day scientific sessions, with time for tours and a banquet. The congress language is English, with facilities for translation, and the closing date for submission of papers is March 31 st 1974. The registration fee is 40 dollars U.S. if sent before March 31 st, otherwise 50 dollars. There are facilities for those accompanying delegates. Accommodation cannot be promised for those sending late applications.

A few application forms are available from the Treasurer, B.A.S.il., but all correspondence should be sent to:

The secretariat, "SPORISMED" - MOTESZ

H 1361 BUDAPEST, POB 32, Hungary.

(Programme received by BASM 12.1.74) 